\title{
KOMPETENSI PENYULUH PERTANIAN BPP HARAU DALAM MENYUSUN PERENCANAAN PROGRAMA PENYULUHAN MENUJU IMPLEMENTASI KOSTRATANI KECAMATAN HARAU
}

\section{COMPETENCY OF BPP HARAU AGRICULTURAL EXTENDERS IN DEVELOPING THE PLANNING OF THE EXTENSION PROGRAM FOR THE IMPLEMENTATION OF KOSTRATANI IN HARAU DISTRICT}

\author{
Dedeh Kurniasih ${ }^{1)^{*}}$, Nila Sari ${ }^{2)}$, Netty Yuliarti ${ }^{3)}$, Khazy Anty ${ }^{4)}$ \\ 1,2,3,4) Dosen Jurusan Budi Daya Tanaman Pangan, Politeknik Pertanian Negeri Payakumbuh, Kab. Limapuluh \\ Kota, Indonesia \\ *penulis korespondensi \\ ${ }^{1)}$ dedehkusnanii03@gmail.com; ${ }^{2)}$ nilasumbar@ gmail.com; ${ }^{3)}$ netti.yuliarti62@ gmail.com; \\ ${ }^{4)}$ khazyanty59.gmail.com
}

\begin{abstract}
Abstrak
Aspek yang menjadi tolok ukur dari keberhasilan pembangunan pertanian ini adalah produktivitas, kualitas dan kontinuitas. Untuk mewujudkan keberhasilan tersebut, Kementrian Pertanian mencanangkan kegiatan yang diberi nama Komando Startegi Pembangunan Pertanian (Kostratani). Kostratani adalah pusat kegiatan pembangunan pertanian tingkat kecamatan, yang merupakan optimalisasi tugas, fungsi dan peran Balai Penyuluh Pertanian (BPP) dengan memanfaatkan IT dalam mewujudkan kedaulatan pangan nasional. Untuk mewujudkannya harus tersedia sarana prasarana, pelatihan untuk mendukung SDM dan SDM (penyuluh pertanian) yang berkompeten. Kompetensi ialah pengetahuan, keterampilan dan kemampuan yang ditampilkan oleh seseorang penyuluh dalam konteks pelaksanaan tugas atau pekerjaannya sebagai penyuluh pertanian. Tujuan penelitian ini yaitu mengidentifikasi kompetensi penyuluh pertanian BPP Harau Dalam Menyusun Programa Penyuluhan. Penelitian ini dilaksanakan Maret sampai Oktober 2020 di BPP Kecamatan Harau dengan jumlah responden 8 orang penyuluh. Penelitian ini menggunakan analisis statistik deskriptif. Hasil penelitian ini menunjukkan bahwa kompetensi penyuluh BPP Harau dalam menyusun programa penyuluhan memiliki nilai rataan skor 2,9 dan tergolong kategori kompeten.
\end{abstract}

Kata kunci: kompetensi, kostratani, penyuluhan

\begin{abstract}
Aspects that measure the success of agricultural development are productivity, quality and continuity. To realize it, the Ministry of Agriculture launched an activity called the Agricultural Development Strategy Command (Kostratani). Kostratani is the center of agricultural development activities at the sub-district level, which is the optimization of the tasks, functions and roles of the Agricultural Extension Center (AEC) by utilizing IT in realizing national food sovereignty. To make it happen, there must be infrastructure, training to support competent human resources and human resources (agricultural extension workers). Competence is the knowledge, skills and abilities displayed by an extension worker in the context of carrying out his duties or work as an agricultural instructor. The purpose of this study is to identify the competence of agricultural extension workers BPP Harau in Developing Extension Programs. This research was conducted from March to October 2020 at BPP Harau District with a total of 8 instructors as respondents. This study uses descriptive statistical analysis. The results of this study indicate that the competence of BPP Harau instructors in preparing extension programs has an average score of 2.9 and is categorized as competent.
\end{abstract}

Keywords: boarding, competence, counseling 


\section{Pendahuluan}

Aspek yang menjadi tolok ukur dari keberhasilan pembangunan pertanian ini adalah produktivitas, kualitas dan kontinuitas. Berdasarkan Peraturan Menteri Pertanian Republik Indonesia (Permentan RI) No 49 th 2019, untuk mewujudkan keberhasilan tersebut, Kementrian Pertanian mencanangkan kegiatan yang diberi nama Komando Startegi Pembangunan Pertanian (Kostratani).

Kostratani adalah pusat kegiatan pembangunan pertanian tingkat kecamatan, yang merupakan optimalisasi tugas, fungsi dan peran Balai Penyuluh Pertanian (BPP) dengan memanfaatkan IT dalam mewujudkan kedaulatan pangan nasional (Permentan, 2019). Kostratani memiliki lima peran di antaranya adalah pusat data dan informasi, pusat gerakan pembangunan pertanian, pusat pembelajaran, pusat konsultasi agribisnis dan pusat pengembangan jejaring kemitraan.

Provinsi Sumatera Barat adalah salah satu provinsi yang merencanakan kegiatan Konstra Da (Kabupaten/Kota) dan Kostratani (Kecamatan) di tahun 2020 dan 2021. Sebaran Konstra Da di Provinsi Sumatera Barat tahun 2020 sebanyak 10 kabupaten/kota dan 88 kecamatan. Kabupeten Lima Puluh Kota adalah salah satu kabupaten di Sumatera Barat yang merencanakan kegiatan Kostratani di tahun 2020 yang tersebar di tujuh kecamatan, salah satunya adalah kecamatan Harau.

Kegiatan Kostratani ini mewujudkan kecamatan menjadi pusat pembangunan pertanian dan BPP sebagai server data dan potensi wilayah. Oleh karena itu untuk mewujudkannya harus tersedia sarana prasarana, pelatihan untuk mendukung SDM dan SDM (penyuluh pertanian) yang berkompeten. Penyuluh yang berkompeten artinya penyuluh yang mampu menjalankan tugas baik di kantor (BPP) maupun di lapangan sesuai dengan kebutuhan masyarakat.Kecamatan Harau memiliki sembilan petani yang masing-masing bertugas di 11 desa di Kecataman Harau. Selain menjalankan tugasnya di BPP, penyuluh ini menjalankan tugasnya di lapangan sesuai dengan wilayah kerja masing-masing yang telah disusun di awal tahun. Penyuluh pertanian di Kecamatan Harau dalam mendukung tugas dan fungsinya mendapatkan pelatihan rutin oleh Dinas Pertanian setempat dan BPTP Sumatera Barat. Pelatihan ini dilaksanakan dua kali dalam satu minggu, dan materi yang diperoleh oleh penyuluh sesuai dengan kebutuhan masyarakat di lapangan.

Dalam rangka perencanaan implementasi Kostratani di Kecamatan Harau, penyuluh pertanian memiliki tugas sebagai pusat pembelajaran, di antaranya adalah mampu mengidentifikasi inovasi teknologi, sebagai demplot atau sekolah lapang, mampu mengimplemntasi inovasi teknologi, dan sebagai bimtek atau teleconference. Keberhasilan Kostratani di Kecamatan Harau ditentukan oleh penyuluh, karena penyuluh yang memiliki tugas paling banyak dalam mendampingi petani di lapangan. Keberhasilan pelaksanaan penyuluhan sangat ditentukan dari rencana yang sebelumnya disusun oleh penyuluh. Dengan demikian, dirasa sangat perlu dilakukan penelitian mengenai kompetensi penyuluh pertanian BPP Harau dalam menyusun perencanaan programa penyuluhan menuju implementasi Kostratani di Kecamatan Harau.

\section{Metode Penelitian}

Penelitian ini dilaksanakan pada Bulan Maret sampai Oktober 2020 di BPP Harau Kabupaten Lima Puluh Kota. Jumlah responden penelitian ini yaitu 8 orang penyuluh yang bertugas di BPP Harau. Data dalam penelitian ini terdiri dan data primer dan sekunder. Pengumpulan data primer dalam penelitian ini menggunakan kuesioner yang berisi daftar pertanyaan. Analisis data yang digunakan adalah analisis statistik deskriptif. 


\section{Hasil dan Pembahasan}

\section{Karakteristik Penyuluh BPP Harau}

Karakteristik individu dalam ilmu penyuluhan merupakan bagian dari ranah perilaku yang dapat membawa individu tersebut ke dalam masyarakat. Karakteristik internal penyuluh BPP Kecamatan Harau yang dimakusd dalam penelitian ini adalah ciri-ciri yang ada di dalam diri penyuluh yang keberadaanya berhubungan dengan kompetensi penyuluh dalam melakukan pekerjaannya. Karakteristik internal penyuluh yang diidentifikasii dalam penelitian ini adalah: (1) umur; (2) jenis kelamin; (3) pendidikan formal; (4) pengalaman bekerja. Berdasarkan hasil penelitian, karakteristik internal penyuluh BPP Harau dapat dilihat pada Tabel 1.

Tabel 1 Karakteristik Internal Penyuluh Pertanian BPP Kecamatan Harau

\begin{tabular}{cccc}
\hline $\begin{array}{c}\text { Komponen } \\
\text { Karakteristik } \\
\text { Internal }\end{array}$ & Nilai Skor & Kriteria & $\begin{array}{c}\mathrm{n} \\
\text { (orang) }\end{array}$ \\
\hline Umur (tahun) & $12-25$ & Remaja & 0 \\
& $26-45$ & Dewasa & 6 \\
Jenis Kelamin & $46-65$ & Lansia & 2 \\
& & Laki-Laki & 4 \\
Pend.Formal & & Perempuan & 4 \\
& & SMA & 2 \\
Pengalaman & $8-9$ & D3 - Sarjana & 6 \\
Kerja & & Cugister & 0 \\
Rataan: 11,25 & $9,1-11$ & Berpengalaman & 3 \\
(tahun) & & Berpengalaman & 1 \\
& & Sangat & 4 \\
& & Berpengalaman & \\
\hline
\end{tabular}

Sumber: Olahan data penelitian

Penyuluh di BPP harau terdiri dari empat orang laki-aki dan 4 orang perempuan. Berdasarkan data di atas dapat dijelaskan bahwa 75\% penyuluh di wilayah kerja tersebut 26-45 tahun dan tergolong dalam kategori dewasa. Berdasarkan Badan Pusat Statistik umur produktif seseorang untuk bekerja adalah 15-64 tahun, dengan demikian dapat dikatakan penyuluh di BPP Harau tergolong tergolong usia produktif untuk melaksanakan pekerjaanya. Penelitian Bansir (2008) mengenai kinerja penyuluh menunjukkan hasil yang sama bahwa umur penyuluh yang produktif akan cepat tanggap dalam merespon kebutuhan petani dalam meningkatkan produksi pertanian.

Rahmawati dkk (2019) mengungkapkan bahwa pendidikan merupakan suatu proses pengembangan pengetahuan, keterampilan maupun sikap yang dilaksanakan secara terencana, sehingga memperoleh perubahan-perubahan dalam peningkatan hidup. Tabel 1 menunjuukan bahwa 75\% penyuluh di BPP Harau memiliki tingkat pendidikan jenjang diploma dan sarjana. Hasil identifikasi di lapangan diperoleh Penyuluh di BPP Harau memiliki pola piker yang lebih mengarah ke perencanaan dan implementasi programa penyuluhan. Selain itu penyuluh di wilayah kerja tersebut memiliki kemampuan pemecahan masalah yang dihadapi petani yang cukup baik. Penelitian ini sejalan dengan penelitian yang dilakukan oleh Muslihat dkk (2015) yang menyimpulkan bahwa semakin tinggi pendidikan penyuluh, maka akan semakin tinggi tingkat kompetensinya dalam melaksanakan tugasnya untuk memberikan bimbingan dan pendampingan pada usahatani. 
Sebesar 50\% penyuluh di BPP Harau sudah bekerja sebagai penyuluh lebih dari 11 tahun dan tergolong dalam kategori sangat berpengalaman: Pengalam kerja berpengaruh pada kinerja penyuluh dalam menjalankan tugas dan fungsinya sebagai pendamping kegaitan usaha tani. Semakin lama seseorang berkecimpung di pekerjaan tersebut, semakin banyak pengetahuan dan pengalaman yang dimilikinya, sehingga dengan mudah memecahkan permasalahan yang dihadapi petani. Penelitian inisejalan dengan penelitian yang dilakukan Wicaksono dkk (2016) bahwa pengalaman kerja berpengaruh terhadap kinerja melalui kompetensi penyuluh pertanian. Hal ini berarti meningkatnya kompetensi yang disebabkan oleh semakin bertambah pengalaman kerja penyuluh maka cenderung dapat meningkatkan kinerja penyuluh.

\section{Kompetensi penyuluh BPP Harau dalam menyusun perencanaan programa penyuluhan}

Kompetensi penyuluh pertanian adalah kemampuan penyuluh sebagai agen perubahan di wilayah kerja penyuluh. Kompetensi penyuluh terdiri dari kompetensi teknis dan kompetensi manajerial (Bahua, 2016). Menyusun perencanaan programa penyuluhan termasuk kompetensi manajerial penyuluh di wilayah kerjanya (Anwas, 2011). Perencanaan programa penyuluhan adalah suatu proses yang berkelanjutan dan dirumuskan secara bersama oleh penyuluh dengan masyarakat sasaran yang nantinya akan membawa perubahan ke arah kemajuan.

Berdasarkan hasil penelitian, rataan skor kompetensi penyuluh BPP Harau dalam menyusun perencanaan programa penyuluhan pertanian yaitu 2,9 dan tergolong dalam kategori kompeten. Komponen yang diukur dalam penelitian disajikan pada tabel 2.

Berdasarkan hasil identifikasi di lapangan menunjukan bahwa penyuluh BPP Harau berkompeten dalam menyusun programa penyuluhan karena penyuluh mengidentifikasi masalah dan wilayah kerja sesuai data dan fakta, mengidentifikasi kebutuhan petani, melibatkan petani dalam menyusun perencanaan, membantu petani mencari harga faktor produksi usahatani. Selain itu, dalam menjalankan pekerjaannya, penyuluh bergabung dengan sub sector pertanian. Dalam rangka mensukseskan kostratani di Kecamatan Harau, perencanaan programa penyuluhan disusun dalam bentuk database, dengan tujuan wejudukan kesamaan data antara tingkat kecamatan dan pusat. Hal ini didukung oleh pendapat Herawati (2006) yang menyatakan bahwa ukuran perencanaan program yang baik yaitu analisis fakta dan keadaan, pemilihan masalah berlandaskan kebutuhan, jelas dan menjamin keluwesan, merumuskan tujuan dan masalah, menjaga keseimbangan, proses berkelanjutan dan proses koordinasi evaluasi hasil. 
Tabel 2 Kompetensi penyuluh BBP Harau dmenyusun perencanaan programa penyuluhan

\begin{tabular}{|c|c|c|}
\hline No & $\begin{array}{c}\text { Kompetensi Dalam Menyusun } \\
\text { Perencanaan Programa Penyuluhan }\end{array}$ & $\begin{array}{l}\text { Rataan } \\
\text { Skor*) }\end{array}$ \\
\hline 1 & $\begin{array}{l}\text { Mengidentifikasi wilayah kerja } \\
\text { penyuluhan }\end{array}$ & 2,9 \\
\hline 2 & $\begin{array}{l}\text { Mengidentifikasi potensi wilayah } \\
\text { penyuluhan }\end{array}$ & 2,9 \\
\hline 3 & Mengidentifikasi kebutuhan petani & 3,0 \\
\hline 4 & $\begin{array}{l}\text { Melibatkan petani dalam menyusun } \\
\text { perencanaan }\end{array}$ & 3,0 \\
\hline 5 & Mencari informasi harga faktor produksi & 2,9 \\
\hline 6 & $\begin{array}{l}\text { Bergabung dengan tim sub sektor } \\
\text { pertanian di lokasi penyuluhan }\end{array}$ & 3,0 \\
\hline 7 & $\begin{array}{l}\text { Menyusun programa dalam bentuk } \\
\text { database }\end{array}$ & 2,7 \\
\hline
\end{tabular}

\section{Kesimpulan}

Berdasarkan hasil dan pembahasan dapat disimpulkan bahwa penyuluh BPP Harau berkompeten dalam menyusun perencanaan programa penyuluhan dalam rangka implementasi kostratani di Kecamatan Harau. Beberapa aspek kompetensi tersebut dalam hal mengidentifikasi wilayah kerja penyuluhan, mengidentifikasi potensi wilayah penyuluhan, mengidentifikasi kebutuhan petani, melibatkan petani dalam menyusun perencanaan, mencari infirmasi harga factor produksi, bergabung dengan tim sub sector pertanian di lokasi penyuluhan, dan menyusun programa dalam bentuk database.

\section{Saran}

Berdasarkan penelitian yang telah dilakukan penulis memberikan saran dianatarnya 1) penyuluh lebih meningkatkan kompetensinya dalam pemanfaatan IT untuk penyusunan perancanaan maupun pelaksanaan penyuluhan, 2) dokumen perencanaan sebaiknya tersusun lengkap setiap tahunnya, dan 3) perencanaan disusun bedasarkan permasalahan yang sedang terjadi di masyarakat pada tahun berjalan.

\section{Ucapan Terima Kasih}

Penelitian ini didanai oleh DIPA Politani Payakumbuh dan diucapkan terima kasih kepada seluruh pihak sehingga penelitian ini dapat terlaksana.

\section{Daftar Pustaka}

Anwas, OM. 2009. Pemanfaatan media dalam pengembangan kompetensi penyuluh pertanian (Kasus di Kabupaten Karawang dan Garut, Provinsi Jawa Barat). Disertasi. pada BKP5K kabupaten bogor provinsi jawa barat. Jurnal Sosial Ekonomi dan Kebijakan Pertanian “Agriekonomika” Volume 4. Nomor 2. Hal: $132-153$.

Bahua MI. 2016. Kinerja penyuluh pertanian.Yogyakarta: Deepublish

Bansir, M. 2008. Analisis pengaruh faktor-faktor yang mempengaruhi kinerja penyuluh pertanian di kabupaten bulungan Kalimantan timur. Jurnal Penyuluhan. Volume 5. Nomor 2. Hal: $73 \quad-83$. 
Herawati, pulungan ismail. 2006. Faktor-faktor yang berhubungan dengan partisipasi kontaktani dalam perencanaan program penyuluhan pertanian. Jurnal Penyuluhan. Volume: 2. Nomor: 2. Hal 1-8.

Muslihat, E., Azhar, A., Kusmiyati, K., dan Woro, I. 2015. Kompetensi penyuluh pertanian dalam penyusunan rancangan usaha agribisnis padi pada BKP5K kabupaten bogor provinsi jawa barat. Jurnal Sosial Ekonomi dan Kebijakan Pertanian “Agriekonomika” Volume 4. Nomor 2. Hal: 132 - 153.

Rahmawati, Baruwadi M, Bahua MI. 2019. Peran kinerja penyuluh dan efektivitas pelaksanaan penyuluhan pada program intensifikasi jagung. Jurnal Sosial Ekonomi Pertanian. Volume 15. Nomor 1. Hal $56-$ 70 .

Permentan, 2019. Peraturan Menteri Pertanian Tentang Komando Strategi Pembangunan Pertanian. http://www.tanamanpangan.pertanian.go.id. Diakses pada: 23 Maret 2019.

Wicaksono, P., Sugiyanto., Mangku P. 2016. Faktor- faktor yang berkontribusi terhadap kinerja dan kompetensi penyuluh pertanian pada jenjang jabatan penyuluh pertanian ahli (Kasus di Malang, Jawa Timur). Jurnal Habitat. Volume $27 . \quad$ Nomor $2 . \quad$ : $\quad 85 \quad-\quad 93$ 